Short reports

\title{
Role of TSH measurements in predicting the outcome of treatment for Graves' disease following drug therapy
}

\author{
Wendy EA Wood
}

\begin{abstract}
Summary
Thyroid-stimulating hormone (TSH)

levels obtained one month after the cessation of anti-thyroid drug treatment were assessed retrospectively for possible use in predicting outcome in 50 patients with a clinical diagnosis of Graves' disease. Thirty-four patients remained in remission at the end of the follow-up period and 16 patients relapsed. Although a TSH level of $<1.2 \mathrm{mU} / 1$ did not discriminate between the two groups, none of the 24 patients who had TSH levels of $>1.2 \mathrm{mU} / 1$ relapsed during the follow-up period, making early discharge from the thyroid clinic possible for these patients.
\end{abstract}

Keywords: Graves' disease, thyroid-stimulating hormone, drug therapy

\section{Introduction}

An ability to predict the outcome of antithyroid drug therapy in patients with thyrotoxicosis would be of great value. The introduction in the mid 1980s of immunoradiometric assays for thyroid-stimulating hormone (TSH) raised the possibility of utilising this assay for assessing outcome. However, Wilson et $a l^{1}$ found that, in patients suffering from Graves' disease treated with carbimazole and triiodothyronine (T3), TSH immunoradiometric assays had no predictive value but thyroid receptor antibody levels predicted $90 \%$ of relapses and remissions. Workers from the same group have more recently confirmed the high specificity and sensitivity of thyroid receptor antibody levels in their hands. ${ }^{2}$ As thyroid receptor antibody assays are not routinely available in the majority of district general hospitals, it seemed appropriate to investigate the use of TSH immunoradiometric assays further, as these are now routinely used.

\section{Patients and methods}

Department of Chemical Pathology, Greenwich District Hospital, Vanbrugh Hill, London SE10 9HE, UK WEA Wood vestigate whether TSH immunoradiometric levels could be of use in assessing the probability of relapse or remission. In all cases
Fifty patients, for whom a TSH level one month after stopping treatment was available, and who had been further followed for at least one year, were assessed retrospectively to in- treatment was tailed off gradually whether titration alone or a block and supplement regime using antithyroid drugs and thyroxine had been used.

The patients ( 45 females, five males) were followed for at least one year following cessation of drug therapy. Patients with hyperthyroidism secondary to multi-nodular goitre were excluded, although minor nodular change was present clinically in some of the older patients assessed as having Graves' disease by the presence of ocular signs. Patients included, therefore, either had predominantly smooth enlargement of the thyroid, with or without eye signs, or some nodularity of the gland with definite ocular signs of Graves' disease. Routine technetium-99m images were not performed but all patients had biochemical and clinical evidence of hyperthyroidism prior to treatment.

The treatment regime consisted initially of carbimazole $30-45 \mathrm{mg}$ daily or an equivalent dose of propylthiouracil. The dose was titrated according to the clinical status of the patient and the results of thyroid function tests. Prior to stopping treatment patients were taking either $5 \mathrm{mg}$ of carbimazole or $50 \mathrm{mg}$ of propylthiouracil. Nine patients, who either became rapidly hypothyroid or had other difficulties with the titration regime, had an appropriate dose of thyroxine added to their regime, together with a blocking dose of antithyroid drugs. At the end of the treatment period, thyroxine was stopped and the antithyroid drug tailed off over a period of a month. All patients were treated for at least one year except one who was treated for six months.

Samples were obtained for TSH immunoradiometric measurements at one month following cessation of treatment. The sample was also assayed for total thyroxine and, if the TSH measurement were suppressed, for free triiodothyronine. The patients included in this survey all had thyroxine and, when appropriate, free triiodothyronine levels within the laboratory reference range. All patients had been followed at approximately three-monthly intervals for a minimum of one year. Recurrence was first detected biochemically but of this group all but one, who had rapidly changing thyroid function, were also clinically toxic.

TSH immunoradiometric levels were measured using one of two assays. For most of the survey the Sucrosep (Boots Celltech) assay was 
used. When this became unavailable the Delphia (Pharmacia) assay was introduced. The correlation of the two assays over a range of Sucrosep TSH values of $0.13-4.7 \mathrm{mU} / 1$ was $r=0.93 \quad(p=<0.01)$. The between-assay coefficients of variation of the two assays were: Sucrosep: $6.3 \%$ at a value of $28 \mathrm{mU} / 1,6.5 \%$ at $6.0 \mathrm{mU} / 1$ and $8.5 \%$ at $1.2 \mathrm{mU} / 1$. Delphia: $5.3 \%$ at a value of $22 \mathrm{mU} / 1$ and $6.1 \%$ at a value of $1.1 \mathrm{mU} / 1$. The data were analysed using the Wilcoxon Rank test.

\section{Results}

The figure shows the TSH values one month after stopping treatment in two groups of patients, those who had become thyrotoxic by the end of the year of follow-up and those who remained in remission. Thirty four patients (30 female, four male: mean age $\pm s d, 43 \pm 14$ years) were in remission at one year; 16 patients (15 female, one male: mean age $37 \pm 13$ years) relapsed during the year of follow-up. The mean TSH level for the remission group was $1.37 \pm 0.82 \mathrm{mU} / 1$ and for the recurrence group was $0.43 \pm 0.38 \mathrm{mU} / \mathrm{l}$. The TSH levels between the recurrence and remission groups were statistically significantly different $(p<0.01)$. Twenty one of the 34 patients, in whom there were no recurrence during the year, had a TSH immunoradiometric level of greater than $1.2 \mathrm{mU} / 1$ at one month.

TSH levels of $<1.2 \mathrm{mU} / 1$ did not discriminate between relapse and remission; 13 patients who remained in remission had TSH values of $<1.2 \mathrm{mU} / 1$ as did all 16 patients in the relapse group, giving a predictive value for recurrence of $55 \%$. A TSH level of $>1.2 \mathrm{mU} / 1$ gave a predictive value for remission of $100 \%$ for this study. Seven of the nine $(78 \%)$ patients on block and supplement remained in remission as opposed to $66 \%$ of the titrated patients. This may have biased the survey in favour of remission but did not alter the predictive value of the TSH level of $>1.2 \mathrm{mU} / 1$.

\section{Discussion}

The ability to predict remission or recurrence following anti-thyroid treatment has proved difficult. Wilson et al have demonstrated that, in their hands, an assay for TSH receptor antibody carried out at the end of a 12-month period following cessation of anti-thyroid treatment accurately predicted $93 \%$ of their relapses and $95 \%$ of remissions. Their assay for thyroid-stimulating antibodies was less successful in discriminating between the two groups, showing the importance of taking into account methodological differences. ${ }^{2}$

The prospective multicentre study on the prediction of relapse following antithyroid

1 Wilson R, Semple CG, Reid AM, Glen JH, McKillop JH, Thomson JA. Can thyroid stimulating hormone levels by TSH (IRMA) predict relapse of thyrotoxicosis following carbimazole treatment? Postgrad Med F 1987; 63: 755-6.

2 Wilson R, Fraser WD, McKillop JH, Thomson JA. The prognostic value of TSH receptor binding and thyroid stimulating antibodies following antithyroid drug treatment of Graves' disease. Acta Endocrinol (Copenh) 1989; 121: 666-70.

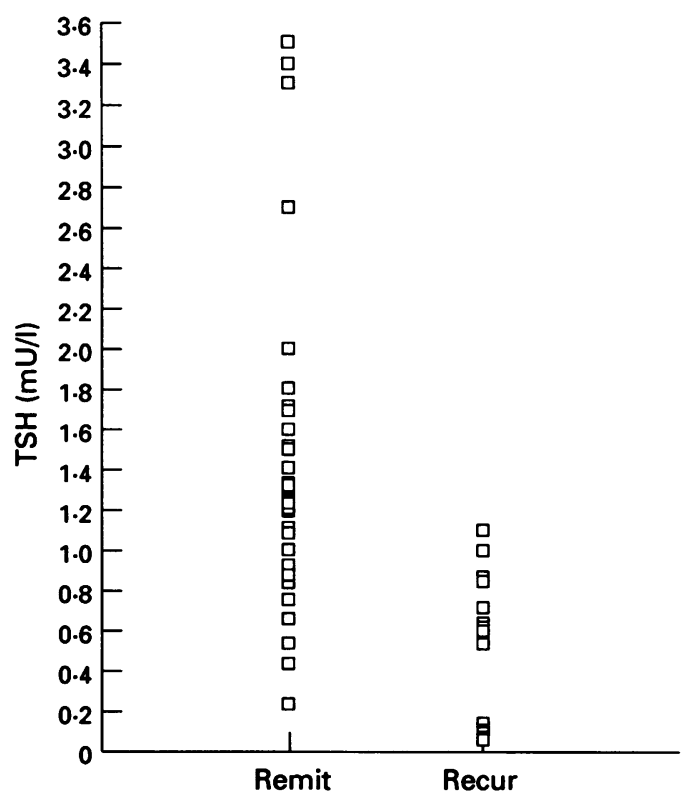

Figure TSH levels one month after stopping treatment

\section{Summary}

- after successful drug treatment for Graves' disease, no patient with a TSH level of $>1.2 \mathrm{mU} / 1$ relapsed

- such patients could be discharged from regular follow-up in a thyroid clinic

drugs in Graves' disease demonstrated that no individual test or observation had sufficient specificity to be of clinical use. ${ }^{3}$ This confirmed the findings of Weetman et $a l^{4}$ who had demonstrated in their prospective study, that a higher free thyroxine level at the outset of treatment was the only significant marker but was little value in the individual case. This study has addressed the TSH value at one month alone and has not taken into account the age of the patient, the size of the goitre or TSH levels prior to stopping treatment, all of which could have contributed to the predictive value of the TSH. However, with a biochemically monitored treatment regime, TSH levels of $>1.2 \mathrm{mU} / 1$ one month after the cessation of treatment can have a valuable role in predicting remission. No patient with a TSH level of $1.2 \mathrm{mU} / 1$ or greater relapsed within one year of cessation of therapy. It would, therefore, be possible to recommend early discharge of such patients from the thyroid clinic.

I wish to thank Dr Philip Marsden, Consultant Physician at Greenwich District Hospital and Dr Patrick O'Gorman, retired Consultant Chemical Pathologist at the same hospital, for their help and advice in preparing this paper. 3 Schleusener $\mathrm{H}$, Schwander J, Fischer C, et al. Prospective multicentre study on the prediction of relapse after Acta Endocrinol (Copenh) 1989; 120: 689-701.

4 Weetman AP, Ratanchaivutong S, Middletone GW, et al. Prediction of outcome in Graves' disease after carbimazole treatment. $Q \mathcal{F}$ Med 1986; 59: 409-19. 